\title{
O QUE AS CRIANÇAS CONTAM DO/NO CORPO NOS ESPAÇOS DA EDUCAÇÃO INFANTIL
}

\section{WHAT CHILDREN TELL OF/IN THE BODY IN THE SPACES OF CHILD EDUCATION}

\author{
Fernanda Ferreira de Oliveira ${ }^{1}$
}

\begin{abstract}
Resumo: Esse texto é um relato de experiência, que pretende, a partir de narrativas do trabalho pedagógico, pensar e evidenciar a significação do corpo das crianças pequenas nos espaços da Educação Infantil. Os registros analisados permitem compreender como elas reconhecem os corpos e a maneira como estes são intencionados nos espaços e tempos desse cotidiano infantil. É pelo / com / no corpo que vivenciam processos de criação, imaginação, experimentação e percepção que constituem a infância. Tal experiência se deu com grupo de crianças de 4 e 5 anos de idade no ano de 2019.
\end{abstract}

Palavras-chave: Corpo; criança; educação infantil.

Resumen: This text is an experience report, which intends, from the narratives of the pedagogical work, to think and highlight the meaning of the body of young children in the spaces of Early Childhood Education. The analyzed records allow us to understand how they recognize the bodies and the way they are intended in the spaces and times of this children's daily life. It is through / with / in the body that they experience processes of creation, imagination, experimentation and perception that constitute childhood. This experience took place with a group of 4 and 5-year-old children in 2019.

Palabras claves: Body; child; child education.

\section{Introdução}

Este artigo apresenta algumas reflexões e inquietações a partir das minhas experiências como professora-pesquisadora da Educação Infantil, de saberes construído na relação da prática com os conhecimentos historicamente constituídos. E para demonstrar essa vinculação produzida na ação docente o corpo é colocado como prioridade da discussão, porque pensar em educação de criança pequena é pensar em corpo. Pois, essa ao estabelecer conexão com o mundo utiliza-se de um repertório significativo e rico em movimentação corporal como mexer, deslocamento, pegar, segurar, arrastar, deslizar, cantar, falar, esconder, torcer, olhar, enfim um corpo presente e que é suporte da recepção da experiência tendo no espaço-tempo da educação infantil um parceiro paras todas essas realizações.

E essa dimensão do corpo da criança que deve ser observada na educação que pensa a perspectiva estética e leva em consideração à "sensação" e percepção sensível dos sentidos. Por isso, que ao constituir essa reflexão ao mesmo tempo em que evidencio o que as crianças fazem na educação infantil, busco compreender o quanto elas se apropriam de seus corpos e permitem, ou não, realizar ações nos espaços da pequena infância. E, que por sua vez manifestam sua capacidade criativa, inventiva e imaginativa apresentando um corpo dilatado de expressões.

Outro ponto de relevância é como reconheço meu corpo em consonância com os corpos das crianças numa teia de corpos, no sentido, de como a professora identifica essa necessidade

\footnotetext{
${ }^{1}$ Professora de Educação Infantil na Rede Pública Municipal de Piracicaba - Mestra em Educação - Doutoranda em Educação PPGE UNIMEP. E-mail: nandaferreira@ hotmail.com.
} 
corporal da criança que se dilata a partir da sua corporalidade, ou seja, no encontro do corpo da criança que se afeta com a mobilidade da adulta.

Tal compreensão está alicerçada a partir da visão de criança que tomo como primordial na relação da educação de crianças pequenas, não só, mas no contato com a vida cotidiana que ao vê-las para além do seu marco biológico a considera como ator social, produto e produtora de cultura, sujeitos históricos, capazes de construir olhares interpretativos do/no mundo, que pensam, agem, sentem como seres singulares e sujeitos de direito. Constroem-se nas relações sociais, aprendendo incorporando práticas culturais, que devem ser ouvidas e ter vez nos espaços da educação infantil, conforme Kramer e Bazílio (2003, p. 91).

[...] reconhecer o que é específico de infância - seu poder de imaginação, fantasia, criação - é entender as crianças como cidadãos, pessoas que produzem cultura e são nelas produzidas, que possuem um olhar crítico que vira pelo avesso a ordem das coisas, subvertendo essa ordem. Esse modo de ver as crianças pode ensinar não só a entendê-las, mas também a ver o mundo a partir do ponto de vista da infância, pode nos ajudar a aprender com elas.

E neste processo de pensar a criança pequena o corpo torna-se a possibilidade da brincadeira, de sentimento e expressão.

\section{O corpo nos espaços da educação infantil}

Quando adentramos no espaço da Educação Infantil com um olhar mais sensível, afinado e receptivo vislumbramos um território de experimentação, exploração e educação de meninas/os pequenas/os e adultos/as em que as diversas sensações se encontram num ambiente que é diferente, mas que irá lhe deixar marcas.

Nesse sentido, pensar nesse espaço é relevante, porque deve ser um lugar propiciador para que as crianças pequenas possam produzir as culturas infantis (FARIA, 2003; PRADO, 2009). Como lugar possibilitador do agir para si mesma e para outro, construindo o significado da autonomia, reorganizando os espaços e tempos. Assim como contribui Ambrogi (2011, p. 65), "O espaço, nesse sentido, pode igualmente proporcionar à criança as múltiplas formas de expressão pelos usos de linguagens e suas formas de criação". E que o corpo é o viés das expressões e das linguagens.

A movimentação das crianças no espaço da educação infantil implica em novos arranjos que possibilitem múltiplas formas de expressões, e ao estarem nesses espaços elas constroem sua forma de ser e estar no mundo.

Esse jogo e suas formas de expressão que vinculam-se com a brincadeira, o que pode ser traduzido como a busca pela livre expressão, pela possibilidade de testar sem compromisso com resultado, cujo horizonte é ilimitado de possibilidades. Essa liberdade de experimentação é um aspecto almejado pelos grandes artistas, que buscam novas composições, muita vezes apoiados na liberdade observada nas crianças em seu jogo e em suas brincadeiras, expressões da criação livre das certezas. (AMBROGI, 2011, p. 65)

Gobbi (2007, p. 65), menciona que ao pensar na escola da infância como território de invenção em que, "A proposta é, como se vê, sair das vestes rígidas de um dia a dia rotineiro, e transbordar no cotidiano de uma escola que contemplem as crianças, suas culturas e suas criações”. 
Os espaços que compõem a Educação Infantil devem ser um convite à exploração do movimento corporal em diferentes escalas, e para as crianças esse espaço pode representar distintas atmosferas que se revelam como "o espaço-alegria, espaço-medo, espaço-proteção, o espaço-mistério, espaço-descoberta" (LIMA, 1989, p. 30), ou seja, que existam espaços no espaço, na dimensão do imaginar, fantasiar e sonhar.

Bachelard também evidencia essa duplicidade pedagógica do espaço em sua obra "A poética dos espaços" (2000), trata da relação existente entre o espaço físico convertido em sonhos no espaço onírico em que sensibilidade, afetividade, desfrute, intervenção, contradição, oposição são constituintes dessa percepção do espaço num processo dialética que se estabelece do mundo exterior e do interior.

Outro autor que trabalha com essa perspectiva dual e poética do espaço é Walter Benjamin dizendo que "as crianças formam seu próprio mundo de coisas, um pequeno mundo inserido no grande" (2009, p. 58), a potência do espaço micro no macro revela a capacidade imaginativa das/dos pequenas/pequenos.

Esses espaços, alterados ou naturais, promotores de ações de liberdade revelam e potencializam as curiosidades das crianças tornando possível a construção das múltiplas linguagens, que devem ser valorizadas, ou seja, espaços/tempos da educação infantil que impulsionam as expressões do/no corpo das crianças enriquecendo as formas como se organizam, exploram e criam. Esses pontos incidem nas experiências de processos inteiros, sem a segmentação e a parcialização do conhecimento.

O espaço físico é um elemento fundamental para uma Pedagogia da Educação Infantil, nesse sentido, nos remete a pensar sobre a importância de nutrir nas crianças vivências capazes de tocar, mexer e sensibilizar. Espaços que permitem grandezas e pequenezas, como nos apresenta Manoel de Barros em seu poema - "Cresci brincando no chão, entre formigas. De uma infância livre e sem comparamentos (2008, s/n).

\section{Sabemos que toda criança necessita de um ambiente potente}

Este relato localiza-se em um espaço de educação infantil, num bairro periférico da cidade de Piracicaba- Sp. Trata-se de uma escola de educação infantil pública, de médio porte, com aproximadamente 273 crianças organizadas por faixas etárias, em períodos integral e parcial, com idades entre 03 meses a 06 anos.

A escola orienta suas ações por pressupostos da Pedagogia da Infância $^{2}$ (2013), constituída na interface dos diferentes campos das ciências humanas (Sociologia, História, Psicologia, Filosofia, Antropologia e Geografia), mas, principalmente porque acredita que a infância é uma construção social e compreende que é importante formar seres humanos que entendam que o outro faz parte da construção da sua própria identidade. Portanto, o cotidiano dessa educação infantil, especificamente o espaço e ação pedagógica, é organizado a partir de premissas, que já foram apresentadas anteriormente, que consideram a criança como produto e produtora da cultura, atores sociais e de direito, com uma intenção educacional que possibilita as mais diferentes maneiras de construção de experiências, tendo na brincadeira sua centralidade.

\footnotetext{
${ }^{2}$ Gramática pedagógica relacionada aos modelos pedagógicos propostos à educação infantil.
} 


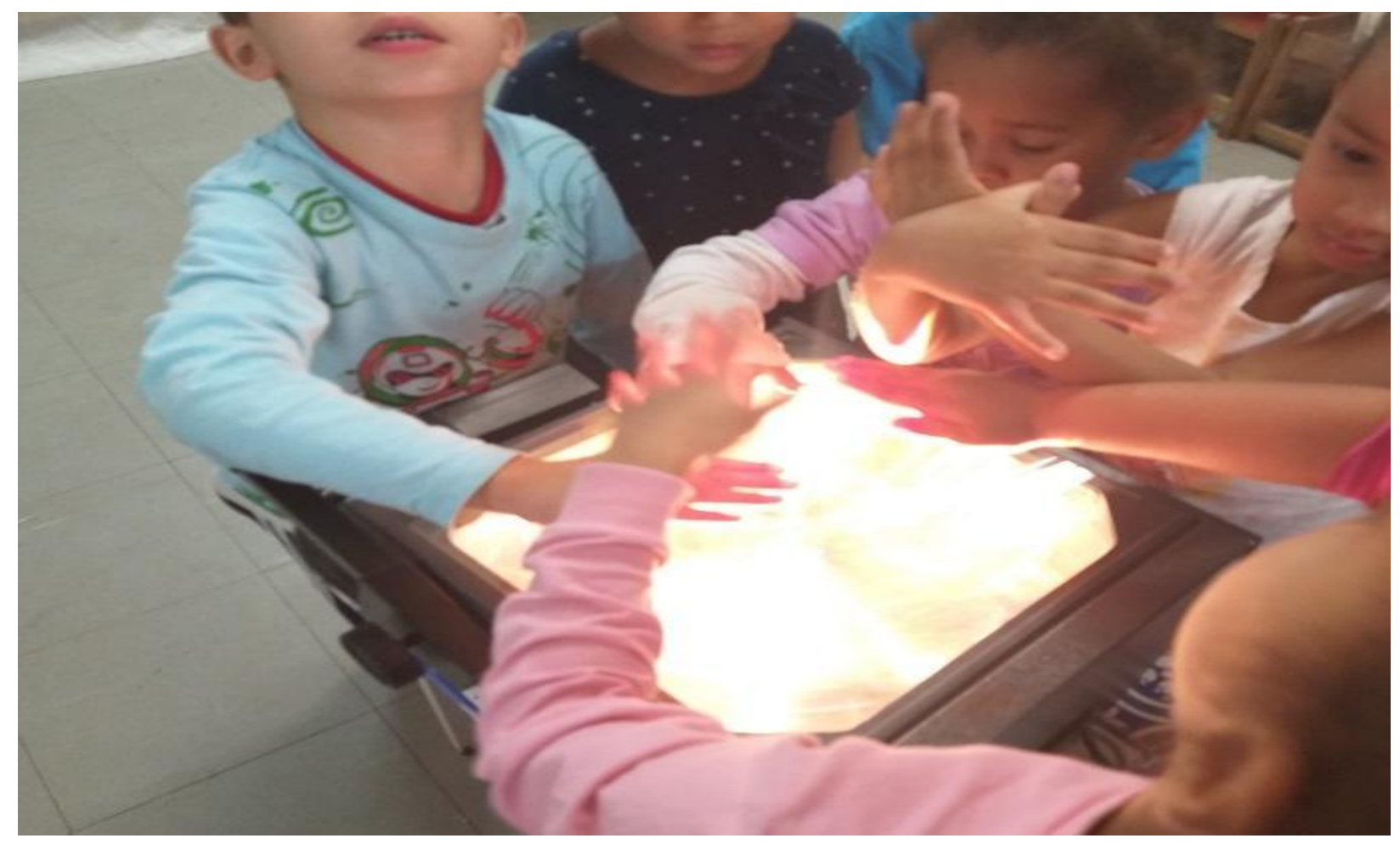

A escola, assumindo a Pedagogia da Infância como fundamento de seu trabalho, por acreditar na existência e necessidade de uma pedagogia direcionada as crianças que estão na educação infantil, dispõe da concepção do currículo emergente (RINALDI, 1999). É uma perspectiva de planejamento curricular na educação infantil em que as docentes formulam objetivos educacionais gerais, assim como propostas de eventos e atividades baseados em seus conhecimentos teóricos, políticos e práticos sobre a criança, ou seja, é sustentado pela consistência da formação docente, mas principalmente ele é emergente porque considera o processo do acontecimento educacional, e ao leva-lo em conta compreende que novos elementos não previstos no currículo poderão aparecer. É o que chamamos de brechas.

Sobre os espaços da educação infantil e sua organização é necessário refletir sobre como pensamos as crianças e os modos que produzem suas infâncias, neste sentido, sigo expondo que a leitura que realizei em relação ao grupo de crianças que acompanhei no ano de 2019 possibilitou observar suas necessidades, olhando para as maneiras como elas brincam, do que brincam, as brincadeiras presentes, quais espaços preferem ficar, quais temas apresentados que mais lhe chamam a atenção, os momentos que estão mais quietas e ou excitada, o que trocam entre si. Toda essa "munição" colabora na compreensão e na elaboração da organização dos espaços, que por sua vez se constituíram provocadores da dimensão corpórea das crianças.

Neste sentido, o material organizado na sala, a disposição dos móveis, a ambientação de outros espaços dentro e fora do prédio diz sobre a concepção de crianças, a orientação da prática docente e a proposta pedagógica na qual busco empreender, pois ao assumir os pressupostos que as crianças são capazes de se constituírem criativas, de se expressarem por meio de diferentes linguagens, de afetarem a cultura reconhecemos nelas suas forças e fraquezas entendendo assim sua potência.

Toda essa relação de olhar e ver, de escutar e ouvir as crianças é o que me projetou para produzir espaços convidativos as experimentações do/no corpo das crianças, e não é por menos que tal forma de como os espaços se apresentaram revelam produtos da relação das crianças com esses.

Esse grupo formado por 22 crianças que participaram desse percurso tem idade entre $4 \mathrm{e}$ 5 anos, é uma turma de período integral. O meu contato com elas aconteceu em outros anos por 
meio dos agrupamentos. Inclusive é importante ressaltar que a realização de agrupamentos na educação infantil também é uma questão de princípios da Pedagogia da Infância, pois o encontro entre as idades possibilita a interação entre crianças de faixas etárias diferentes e essa união tem vários efeitos e impactos nas relações cotidianas. Outra questão relevante é que para essas crianças o convívio com a intervenção nos espaços pelas docentes não era uma novidade e sim incorporado nas diferentes intencionalidades da prática pedagógica.

Esse grupo formado por meninas e meninos se constitui muito alegre e brincante. Encantavam-se com as atividades proposta que eram permeadas por aspectos desafiadores, laboriosos, mas também simples e divertidos, elas encontravam-se a si mesma nesse ambiente acolhedor, que propiciava a possibilidade de sentir e perceber suas sensorialidades, de manifestar suas curiosidades e de expressarem as suas diferentes linguagens. Estavam abertas a novos conhecimentos e identificavam no espaço da educação infantil um ambiente acolhedor para suas demandas, e quando participavam da organização dos espaços percebiam que as suas produções e contribuições eram valorizadas nesse processo gerando um sentimento de pertencimento.

As crianças nas suas falas, gestos e movimentação nos/pelos espaços demonstravam o quanto sabiam que o brincar de diferentes formas era prioridade e, por sua vez, revelavam sua capacidade criadora e inventiva. E mesmo quando esse tempo era interrompido, por diversos motivos da rotina, que por sua vez essa poderia ser um espaço fértil de descobertas, mesmo assim as crianças forjavam momentos para continuar a brincadeira até o último instante.

Essas crianças que experimentam e conhecem o mundo pelo corpo necessitam de tempo. Hall (1996) utiliza os termos espaço-tempo juntos, porque acredita que é um conjunto de identidades individuais, mas coletiva ao mesmo tempo, e aqui sem nenhuma pretensão de querer isola-las, mesmo porque venho explicitando sobre o espaço e toda sua dimensão complexa de forma particular, contudo o convite é para pensá-las não como objetos distintos e sim como conceitos.

O tempo como facilitador para o conhecimento do mundo pelo corpo é um intervalo reflexivo. Mas, para falar de tempo debruçaremos em dois autores Larossa (2002) e Staccioli (2018). Se nos constituímos como sujeito da experiência, e por sua vez experiência é algo que nos passa, que nos toca, que nos afeta e temos o corpo como suporte e território de passagem, um lugar em que acolhe as coisas, um espaço sensível de acontecimento, tudo isso demanda tempo. Um tempo no qual é necessário que seja lento para criar intimidade, para fazer, desfazer, olhar, perceber e sentir, uma lentidão e morosidade que permita a receptividade e acomodação das coisas, como uma travessia de uma longa passagem em que o durante é gestacional.

O tempo da criança é lento para poder acontecer, caso o contrário não acontece. A maioria das coisas fascinam as crianças, mas isso acontece porque elas têm tempo, e possuir e tomar o tempo é coisa de uma jornada que não foi interrompida em seus momentos preciosos.

$\mathrm{Na}$ educação infantil nos esforçamos em construir um cotidiano coerente com essa perspectiva, a partir da consciência desse tempo desacelerado. Porque a compreensão desses momentos quando as crianças estão experimentando são importantes para cada qual construir singularmente suas experiências.

\section{Corpo compreende o ambiente ao seu redor}

O sujeito ao expressar pelo seu corpo, e este pode ser o que vai ser descoberto ou o que vai possibilitar o que vai ser desvendado, ele é o suporte e também o caminho. É pelo corpo que as crianças estabelecem relação com o outro, e estar em brincadeira com o corpo experimentando possibilidades de movimentos e comunicação é estar presente nele.

O nosso desafio na educação infantil tem sido reconhecer e legitimar os corpos das crianças em toda a sua complexidade e talento, mas também há nesse contexto um reconhecimento do 
corpo da adulta, da professora, que entende ele como sua morada, que a coloca no mundo e nos permite comunicar, compreender, ser e estar nele. A professora que conhece seu corpo suas possibilidades e limites tem clareza quando pode abrir seu refúgio para os outros, e as crianças sentem essa troca que é constituída pelo toque, pela fala, pelo gesto, pelo contato, pelo olhar e pelo que é oferecido. O corpo pode muitas coisas a partir do entendimento que temos dele e principalmente criar um canal de intercomunicação, uma teia entre corpos, ou seja, do encontro do sujeito com os outros e desses em relação ao espaço, é o que chamamos de estados de atenção em três disposições: o eu, o outro e o espaço (MILLER, 2016).

Esse processo que envolve esses estados de atenção foi possível vivenciá-los com o grupo de crianças, a partir da realização de diferentes momentos do cotidiano da pré-escola. Um episódio, entre vários, em que é possível explicitar sobre a relação que acontece entre o corpo da criança, o espaço e o tempo na educação infantil como potência é o que apresento a seguir:

\section{Pequeno laboratório de bambus no quintal}

Esse grupo de crianças, que foi se constituindo curioso, inventivo e imaginativo, foi surpreendido com uma ambientalização diferente do quintal. Esse espaço situa-se ao lado de sala de referência é utilizado constantemente por elas nas produções e organização de suas brincadeiras, bem como na elaboração, por parte da professora, de ambientes provocativos onde ficam repletos de materiais como artefatos, utensílios, peças, instrumentos e objetos que tem na sua origem, principal os remanescentes da natureza.

Nesse quintal existe uma pirâmide de bambu, ela é móvel e pode ser deslocada de acordo com as necessidades do grupo. Há também enterrada ao fundo do quintal um grande galho de goiabeira que torna suporte para várias coisas.
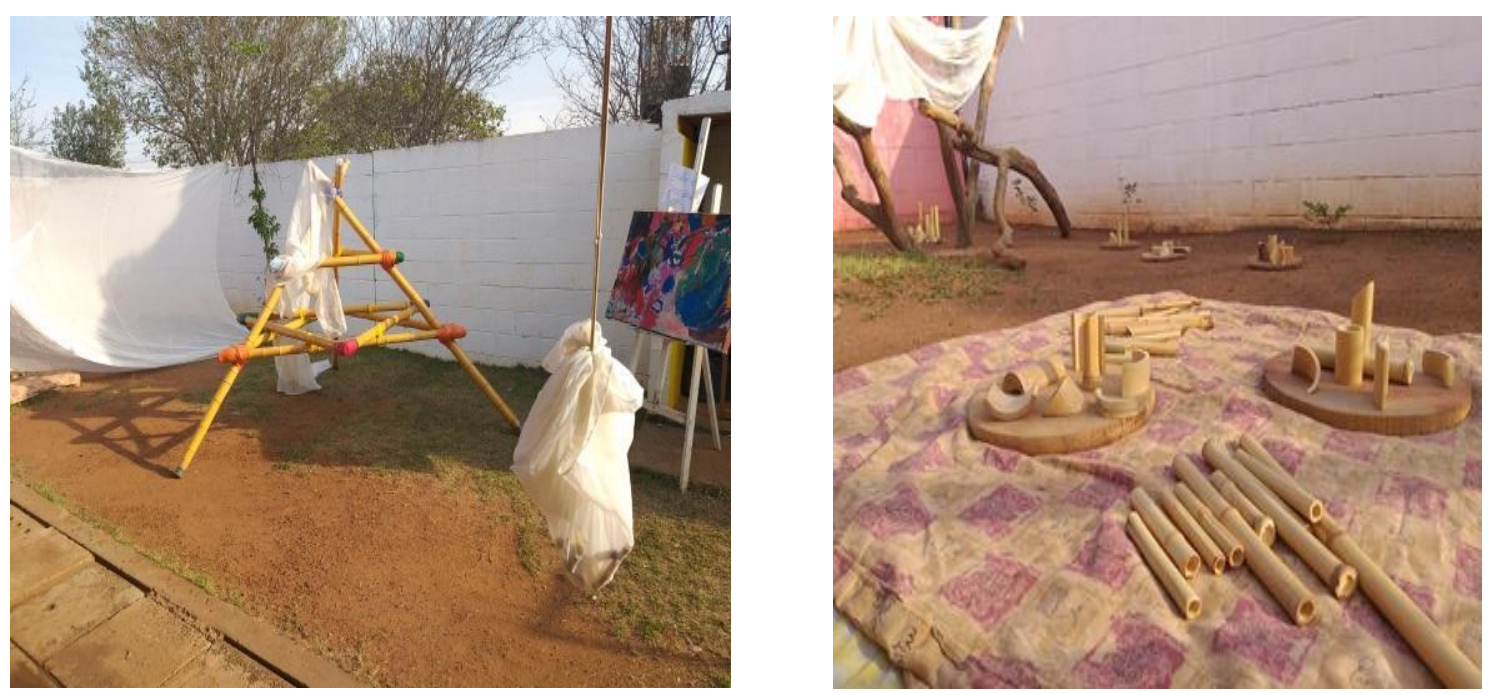

Nesse dia do laboratório de bambus o quintal foi preparado com várias qualidades de bambu, dividido em diferentes tamanhos e de diversas formas e que foram posicionados em níveis; pendurados como pingentes, sobre pequenas mesinhas, pelo chão e espalhados. Outros objetos compuseram junto aos bambus como tecidos e discos de madeiras. Toda essa organização é intencional para que as crianças explorassem ao máximo esta situação, e era uma arrumação provocativa dos corpos das crianças, que tocavam e mexiam nesses materiais investigando-os, pois ofereciam uma diversidade de qualidade de formas, tamanhos, texturas, cheiros. Estavam no baixo, no alto e no mediano, ou seja, possibilitavam as trocas de níveis corporais, além das diferentes posturas como sentado, deitado, ajoelhado, agachado, em pé, nas 
pontas dos pés alcançando com as mãos o que estava alto, que também poderia ser movimentos de balanço, de impulso e de pulo.
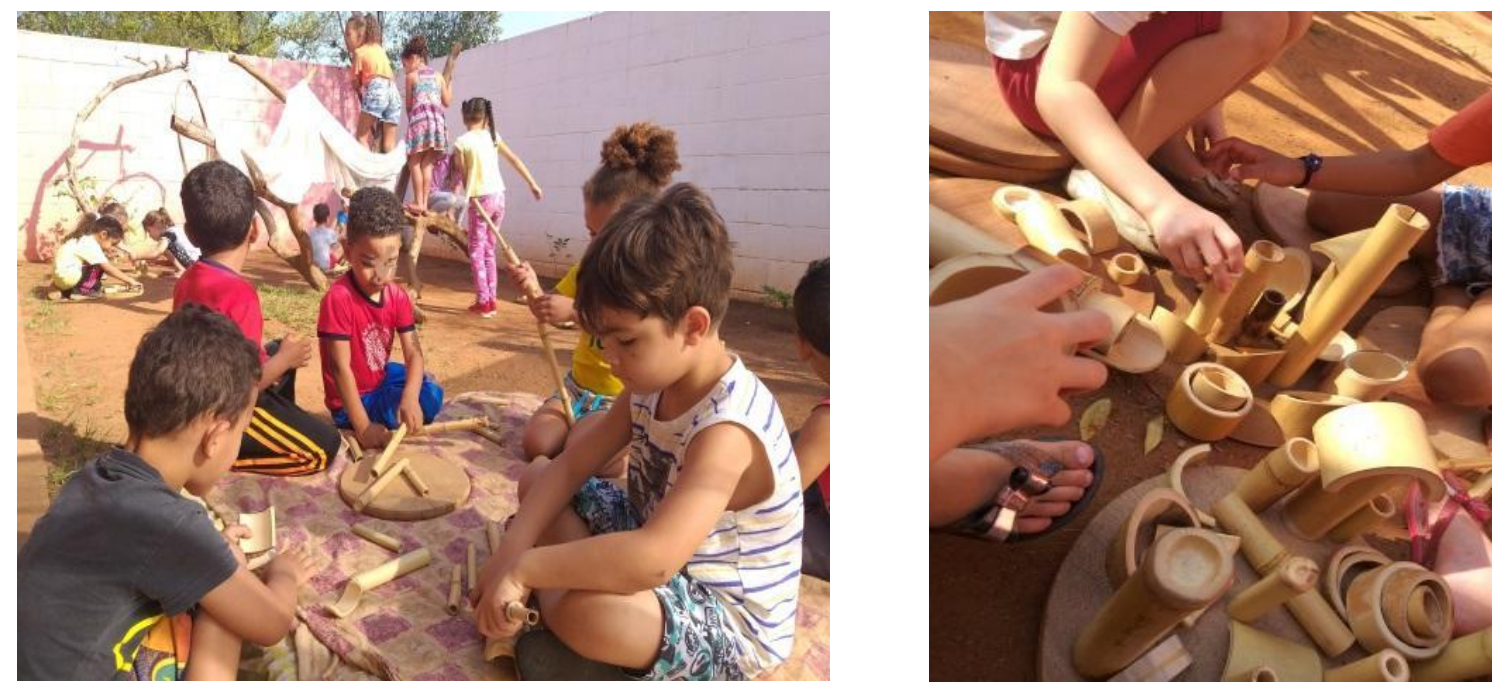

O corpo que desvia os tecidos ou se embola junto a ele constrói um jogo de sensações por meio de suas tessituras que é fosca, mas que permite entrever o outro e o que está acontecendo em seu redor de forma turva ao mesmo tempo em que cria em si uma imagem desfigurada.

Os bambus emitem som quando batidos, então vivências anteriores com músicas, ruídos e som voltam à tona para ser vivenciado ao seu soado. No mesmo sentido, essa presença no acontecimento levou as crianças a criarem esculturas, engenhocas e produtos da cultura a partir da exploração dos materiais e para isso foi necessário equilibrá-las, encaixá-las, nivelá-las, combiná-las.

O galho da goiabeira revestida de tecidos e enganchada com vários pingentes de bambu propiciou um sobe e desce desafiador, e o contorno entre os objetos era difícil necessitando construir uma destreza contorcionista das crianças.

O fazer junto esteve presente tanto nas criações como nos desafios, ou na observação do que o outro está elaborando. Essa manutenção da atenção também se estendeu ao espaço na busca do entorno, e muitas vezes levavam-nas a outras ocasiões e posicionamentos.
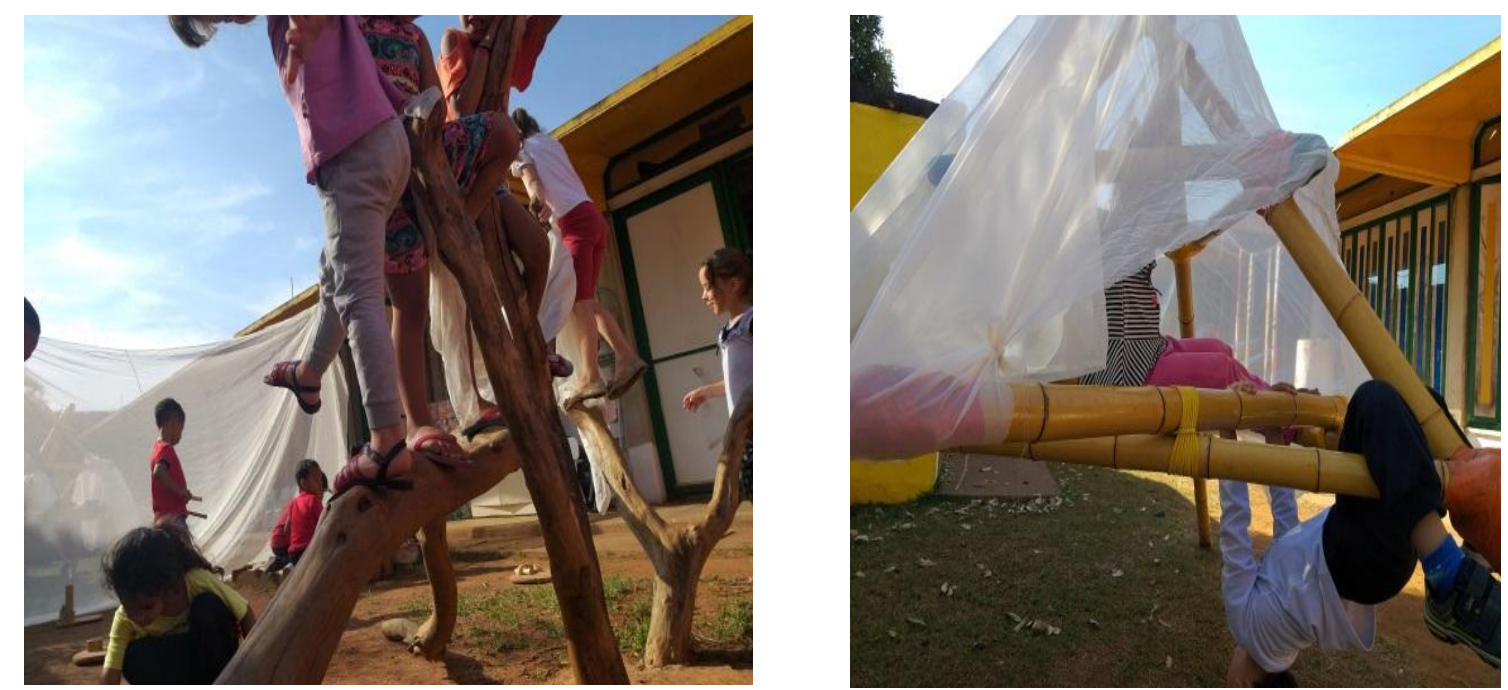
Diante desses desafios corporais que foram apresentados trago as considerações finais, no sentido de convidar para a reflexão sobre a importância da formação de corpos potentes na educação infantil não como algo instrumentalizado, mas como proposta de ampliar o conhecimento do próprio corpo e de suas possibilidades de criação no contato com outro. Alargando a capacidade de comunicação e expressão por meios dos gestos e do movimento, construindo a percepção corporal por meio do espaço e tendo no tempo a oportunidade do acontecimento da experiência no ato de passar, acolher e produzir intimidade.

Trago aqui inquietações sobre corpos de crianças e professoras que muitas vezes são rígidos, encurtados, controlados e acinésicos fruto dessa sociedade contemporânea que não valoriza a dimensão corpórea, em que a sensorialidade vem sendo esquecida e que o espaçotempo vale dinheiro.

Foi possível perceber que as crianças contam do/no corpo que são possuidoras de físicos potentes que possibilitam os processos imaginativos, investigativos e de criação, bem como a capacidade de solucionar e resolver os desafios por meio da corporalidade.

Pensar um espaço educacional em que a dimensão humana é considerada, e o agir e o movimentar das crianças pressupõe novos arranjos no espaço para outras formas de expressões. Requer olhar para os detalhes em que os estados de atenção - eu, outro-espaço - ficam aguçados, e cada pormenor é relevante para construção da experiência.

Enfim faço um convite para que os corpos observem mais a formigas e se mexam como nuvens.

\section{Referências}

AMBROGI, Ingrid Hötte. Reflexões sobre o uso do espaço como garantia para a criação de meninos e meninas pequenas. Pró-Posições, Campinas, v. 22, n. 2, p. 63-73, maio/ago., 2011.

BACHELARD, Gaston. A poética do espaço. Trad. Antonio de Pádua. São Paulo: Martins e Fontes, 2000.

BARROS, Manoel. Memórias inventadas - A terceira infância. São Paulo: Editora Planeta, 2008.

BENJAMIN, Walter. Reflexões: a criança, o brinquedo, a educação. São Paulo: Summus, 2009.

CAMPOS, Maria Malta. Em busca da pedagogia da infância: pertencer e participar. Porto Alegre: Penso, 2013.

FARIA, Ana Lúcia Goulart. O espaço físico como um dos elementos fundamentais para uma pedagogia infantil. In: FARIA A. L. G.; PALHARES, M. (Org.). Educação infantil pós - LDB: rumos e desafios. 4. ed. Campinas: Autores Associados, 2003. p. 67-100.

GOBBI, Marcia Aparecida. Ver com olhos livres: arte e educação na primeira infância. In: FARIA, Ana Lúcia Goulart (Org.). Coletivo infantil em creches e pré-escolas: falares e saberes. São Paulo: Cortez, 2007.

HALL, Stuart. Introduction: who needs identity? In: HALL, S.; DU GAY, P. Questions of cultural identity. Londres: SAGE, 1996.

KRAMER, Sônia; BAZÍLIO, Luiz Cavalieri. Infância, educação e direitos humanos. São Paulo: Ed. Cortez, 2003. 
LARROSA, Jorge. Notas sobre a experiência e o saber de experiência. Revista Brasileira de Educação, Rio de Janeiro, n. 19, p. 20-28, 2002. Disponível em: https://doi.org/10.1590/S141324782002000100003. Acesso em: 05 mar. 2020.

LIMA, Mayumi Sousa. A cidade e a criança. São Paulo: Nobel, 1989.

MILLER, Jussara. A escuta do corpo: sistematização da técnica Klauss Vianna. 3. ed. São Paulo: Summus, 2016.

PRADO, Patrícia Dias. Quer brincar comigo? pesquisa, brincadeiras e educação infantil. In: FARIA, Ana Lúcia Goulart; DEMARTINI, Zeila de Brito; PRADO, Patrícia Dias (Org.). Por uma cultura da infância: metodologia de pesquisa com crianças. 3. ed. Campinas: Autores Associados, 2009.

RINALDI, C. O currículo emergente e o construtivismo social. In: EDWARDS, C.; GANDINI, L.; FORMAN, G. As cem linguagens da criança: a abordagem de Reggio Emilia na educação da primeira infância. Porto Alegre/RS: Artmed, 1999. p. 113-122.

STACCIOLI, Gianfranco. As rotinas: de hábitos estéreis a ações férteis. Revista Linhas, Florianópolis, v. 19, n. 40, p. 54-73, mai/ago., 2018. 